\title{
ТЕОРЕТИЧЕСКОЕ ОБОСНОВАНИЕ И РАЗРАБОТКА РЕЦЕПТУРНОГО СОСТАВА НАПИТКОВ ДЛЯ ПРОФИЛАКТИЧЕСКОГО ПИТАНИЯ С ИСПОЛЬЗОВАНИЕМ БИОЛОГИЧЕСКИ АКТИВНЫХ СОЕДИНЕНИЙ (часть 1)
}

\author{
E.A. Vechtomova, I.Yu. Sergeeva,

\section{THEORETICAL SUBSTANTIATION AND THE DEVELOPMENT OF THE PRESCRIPTION COMPOSITION OF DRINKS FOR PREVENTIVE NUTRITION USING BIOLOGICAL ACTIVE COMPOUNDS (part 1)} V.S. Raynik, V.O. Romanenko

\begin{abstract}
Вечтомова Елена Александровна - канд. техн. наук, доц. кафр. технологии продуктов питания из растительного сырья Кемеровского государственного университета, г. Кемерово.

E-mail: vechtomowa.lena@yandex.ru
\end{abstract}

Сергеева Ирина Юрьевна - д-р техн. наук, доц., зав. каф. технологии продуктов питания из растительного сырья Кемеровского государственного университета, г. Кемерово.

E-mail: sergeeva.76@list.ru

Райник Виталий Сергеевич - асп. каф. технологии продуктов питания из растительного сырья Кемеровского государственного университета, г. Кемерово.

E-mail: rainikwit@mail.ru

Романенко Василий Олегович - канд. техн. наук, повар-универсал ИП Волков А.А., г. Кемерово.

E-mail: romvas-1989@mail.ru

Настоящее исследование посвящено теоретическому обоснованию и практической разработке рецептурного состава напитков для профиилактического питания. Объектами исследований в работе являются безалкогольные напитки, приготовленные на основе растительного сырья, богатого биологически активными соединениями. В качестве основных источников биологически активных веществ были использованы экстракты эхинацеи и гуараны. В работе описаны возможные механизмы воздействия биологически активных веществ растительного сырья и компонентов витаминно-минерального комплекса на организм человека, в частности на предотвращение развития ожирения, ишемической болезни сердца, избыточной массы тела и са-
Vechtomova Elena Alexandrovna - Cand. Techn. Sci., Assoc. Prof., Chair of Plant-Based Food Technology, Kemerovo State University, Kemerovo.

E-mail: vechtomowa.lena@yandex.ru

Sergeeva Irina Yuryevna - Dr. Techn. Sci., Assoc. Prof., Head, Chair of Plant-Based Food Technology, Kemerovo State University, Kemerovo.

E-mail: sergeeva.76@list.ru

Rainik Vitaly Sergeyevich - Post-Graduate Student, Chair of Plant-Based Food Technology, Kemerovo State University, Kemerovo.

E-mail: rainikwit@mail.ru

Romanenko Vasily Olegovich - Cand. Techn. Sci., Universal Cook, SP 'Volkov A.A.', Kemerovo. E-mail: romvas-1989@mail.ru

харного диабета. Исследования проводились 8 Технологическом институте пищевой промышленности Кемеровского государственного университета. Все эксперименты проводили с использованием стандартных методик, принятых в отрасли. При разработке рещептуры напитков особое внимание было уделено вкусо-ароматической составляющей, определяемой в процессе дегустации, а также количественному содержанию биологически активных компонентов в готовом образие с учетом потерь ценных компонентов на технологических стадиях. Среди результатов экспериментальных исследований необходимо отметить обоснование и разработку рещептурного состава напитка с внесением макрои микроэлементов, L-карнитина, экстрактов 
гуараны и эхинацеи. В ходе исследования были составлены рещептуры безалкогольных напитков, определены основные фиизикохимические показатели разработанных образцов, регламентируемые требованиями ГОСТа. Проведена дегустационная оценка. Доказана целесообразность использования растительного сырья, богатого биологически активными веществами, в рецептурах напитков профолактического действия с целью профилактики неинфекционных заболеваний различных органов и систем человека.

Ключевые слова: растительные экстракты, витаминно-минеральные комплексы, профилактические напитки, физическая активность, диетология, ожирение, L-карнитин.

The study was devoted to theoretical justification and practical development of the prescription composition of the drinks for preventive nutrition. The objects of the research were soft drinks cooked on the basis of vegetable materials rich in biologically active compounds. The extracts of echinacea and guarana were used as the main sources of biologically active substances. The study described possible mechanisms of the influence of biologically active substances of plant materials and components of vitamin-mineral complex on human body, in particular on preventing the development of obesity, coronary heart disease, overweight and diabetes. The research was conducted at Technological Institute of Food Industry, Kemerovo State University. All the experiments were carried out using industry standard techniques. When developing the beverage recipe, special attention was paid to the taste and aromatic component determined during the tasting process, as well as to the quantitative content of biologically active components in finished sample, taking into account the loss of valuable components at technological stages. Among the results of experimental studies it is necessary to note the justification and development of the prescription composition of the drink with the addition of macro- and microelements, L-carnitine, guarana and echinacea extracts. During the study nonalcoholic beverage formulations were compiled, the main physical and chemical parameters of the developed samples, regulated by the requirements of state standard specification were determined. The tasting assessment was carried out. The expedien- cy of using plant materials rich in biologically active substances in the formulations of preventive action drinks for the purpose of prevention of noncommunicable diseases of various organs and systems of the person was proved.

Keywords: plant extracts, vitamin and mineral complexes, prophylactic drinks, physical activity, dietetics, obesity, L-carnitine.

Введение. В настоящее время особое внимание ученых направлено на коррекцию и профилактику различных заболеваний. Одним из возможных вариантов такой коррекции является специальное питание, в частности употребление напитков функционального и профилактического действия. Входящее в состав рецептуры напитков сырье обладает широким спектром действия в отношении различных заболеваний, включая избыточную массу тела, вызванную слабым воспалением, сахарный диабет, ишемическую болезнь сердца и другие.

Цель исследования. Теоретическое обоснование и разработка рецептурного состава напитка для профилактического питания.

Задачи исследования: обосновать целесообразность введения в состав напитка в качестве целевых компонентов минеральных веществ в виде неорганических солей исходя из их органолептических характеристик и суточной потребности; осуществить подбор витаминного комплекса; разработать рецептуру безалкогольного напитка профилактического действия на основе подобранных витаминно-минерального комплекса и вкусовых компонентов.

Методы исследования. Все исследования проводились с использованием стандартных методик, принятых в отрасли. Оценка органолептических показателей готовой продукции осуществлялась методом дегустации [1], массовую долю растворимых сухих веществ определяли рефрактометрическим методом [1]; кислотность готового напитка оценивали путем титрования раствором 0,1 M NaOH в присутствии фенолфталеина [1];

Результаты исследования и их обсуждение. Варьируя целевыми компонентами, можно создавать рецептуры напитков для профилактики ожирения на фоне низких физических нагрузок и дефицита минеральных веществ и витаминов (рис.1). 


\section{$Б A B$}

\section{витаминно-минеральный}

комплекс

\section{Сахарный сироп, регулятор кислотности}

\section{Puc. 1. Компонентный состав напитка}

В настоящих исследованиях основу витаминно-минерального комплекса разработанных напитков составили соединения кальция, магния и цинка, витамины группы В и С.

Выбор таких нутриентов основан на результатах многочисленных исследований в области проблем ожирения и механизмов снижения индекса массы тела [2-8, 9-14]. Каждый из этих компонентов отличается направленным действием, и значительные потери даже одного из них могут привести к нарушениям фрункций организма в целом.

С учетом рассчитанного количества, основанного на нормах суточного потребления, были приготовлены модельные растворы мине- ральных солей и проведена их органолептическая оценка, на основании результатов которой для дальнейших исследований были использованы соли $\mathrm{CaCl}_{2}, \mathrm{MgCl}_{2}, \mathrm{Zn}\left(\mathrm{CH}_{3} \mathrm{OO}\right)_{2}$ с учетом их растворимости и органолептических показателей. Целесообразно внесение целевых компонентов в количестве не более $50 \%$ от суточной потребности, так как возможно также их потребление и с другими продуктами во избежание перенасыщения.

В качестве источника витаминов использовали витаминно-минеральный комплекс, разработанный совместно с предприятием ОАО «Кемеровская фрармацевтическая фабрика», состав которого представлен в таблице 1.

Таблица 1

\section{Состав витаминно-минерального комплекса, \%}

\begin{tabular}{|c|c|}
\hline Компонент & Количество \\
\hline $\mathrm{B}_{1}, \mathrm{Mг}$ & 1,2 \\
\hline $\mathrm{B}_{2}, \mathrm{Mг}$ & 5,0 \\
\hline $\mathrm{B}_{6}, \mathrm{Mг}$ & 2,0 \\
\hline $\mathrm{B}_{12}, \mathrm{мкг}$ & 3,0 \\
\hline $\mathrm{C}, \mathrm{мг}$ & 60,0 \\
\hline Магний, мг & 50,0 \\
\hline Кальций, мг & 150,0 \\
\hline Цинк, мг & 12,0 \\
\hline
\end{tabular}

Основными компонентами, которые придают напитку сладость и полноту вкуса, являются сахар и лимонная кислота. Кроме того, лимонная кислота является природным антиоксидантом и консервантом, а сахар имеет большую ценность как источник необходимой энергии.

Учеными $[15,16]$ изучено также влияние новой комбинации L-карнитина, креатина и лейцина на мышечную массу и работоспособность. Карнитин состоит сразу из нескольких амино- кислот и витаминов и выполняет в организме множество функций. Одна из них - транспортировка жировых молекул внутрь клеточных митохондрий, которые «сжигают» жиры в целях получения энергии. Эксперименты показали, что прием карнитина приводит к ускорению сжигания лишнего жира и отодвигает усталость. Доказано, что L-карнитин в сочетании с креатином и L-лейцином значительно улучшил суммарный показатель, который отражает мышечную массу 
и силу, в конце исследования по сравнению с плацебо. Комбинация показала увеличение уровня белка, что приводит к улучшению мышечной силы. Эта новая комбинация может обеспечить потенциальное вмешательство в питание для стимулирования роста мышц и улучшения их физического функционирования.

В качестве источника биологически активных соединений в работе использовали растительное сырье - эхинацею и гуарану, которые вносили в напиток в виде экстрактов. Известно, что эхинацея богата полифенольными соединения- ми, среди которых наибольшая часть приходится на оксикоричные кислоты, способные связывать и выводить из организма радионуклиды. Гуарана является природным стимулятором за счет наличия в своем составе кофеина.

На основании вышеперечисленных результатов исследований была составлена рецептура (табл. 1), изучены основные фризикохимические показатели напитка «Холодок» (табл. 3) и проведена его дегустационная оценка (рис. 2).

\section{Рецептура безалкогольного напитка «Холодок» на 100 дал}

Таблица 2

\begin{tabular}{|c|c|c|c|c|}
\hline Компонент & $\begin{array}{c}\text { Ед. } \\
\text { измерения }\end{array}$ & Количество & $\begin{array}{c}\text { Массовая доля сухих } \\
\text { веществ, \% }\end{array}$ & $\begin{array}{l}\text { Масса сухих } \\
\text { веществ, кг }\end{array}$ \\
\hline Caxap & $\mathrm{K} \Gamma$ & 65,0 & 99,85 & 64,9 \\
\hline Лимонная кислота & $\mathrm{K} \Gamma$ & 3,0 & 90,95 & 2,48 \\
\hline Настой эхинацеи & $\Rightarrow M^{3}$ & 0,012 & 2,0 & - \\
\hline Гуарана & $\mathrm{K} \Gamma$ & 0,6 & 95,0 & 0,59 \\
\hline L-карнитин & КГ & 3,3 & 95,0 & 2,54 \\
\hline Хлорид кальция & Кг & 0,38 & 98,0 & - \\
\hline Ацетат цинка & Кг & 0,28 & 98,0 & - \\
\hline Хлорид магния & КГ & 0,044 & 98,0 & - \\
\hline Витамин $\mathrm{B}_{1}$ & КГ & 0,0012 & 98,0 & - \\
\hline Витамин $\mathrm{B}_{6}$ & Кг & 0,002 & 98,0 & - \\
\hline Витамин $\mathrm{B}_{12}$ & Кг & 0,000003 & 98,0 & - \\
\hline Витамин C & КГ & 0,006 & 98,0 & - \\
\hline $\begin{array}{l}\text { Ароматизатор «Холо- } \\
\text { док»/ «яблочный»/ «ли- } \\
\text { мон-лайм» }\end{array}$ & $д M^{3}$ & 0,4 & - & - \\
\hline Итого масса сухих веществ & КГ & & & 70,75 \\
\hline
\end{tabular}

\section{Физико-химические показатели напитка «Холодок»}

\begin{tabular}{|l|c|}
\hline \multicolumn{1}{|c|}{ Показатель } & Значение \\
\hline Массовая доля сухих веществ, \%, & 6,9 \\
\hline $\begin{array}{l}\text { Кислотность, см }{ }^{3} \text { раствора гидроксида натрия } \\
\text { концентрацией 1 моль/дм³ на } 100 \text { см³ напитка }^{3}\end{array}$ & $1,9 \pm 0,3$ \\
\hline $\mathrm{pH}$ & 4,2 \\
\hline
\end{tabular}

За основу была выбрана классическая дегустационная шкала для безалкогольных напитков, из которой исключена оценка углекислоты. При оценке органолептических показателей анализировали вкус, цвет, аромат.
- Вкус оценивается от 1 до 5 баллов.

- Аромат от 1 до 4 баллов.

- Прозрачность от 1 до 3.

- Цвет от 1 до 3 баллов. 


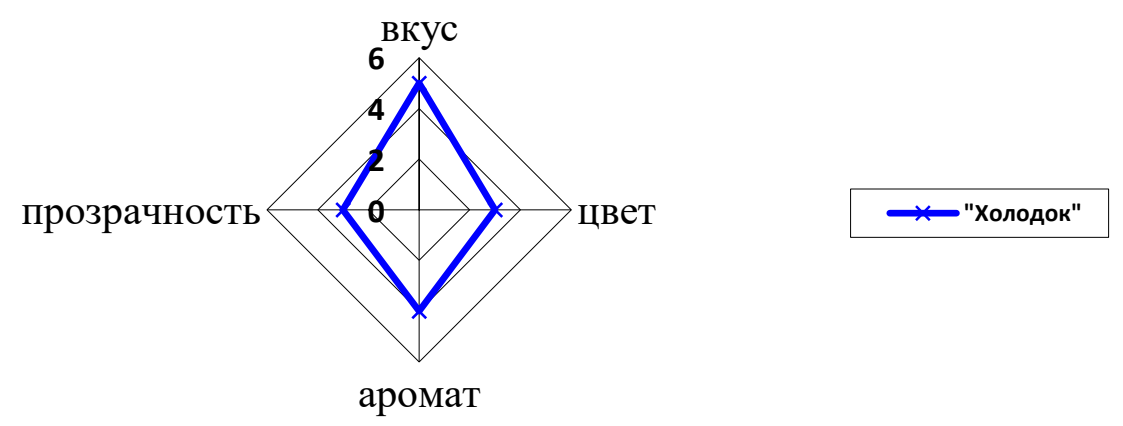

Puc. 2. Органолептический профиль напитка «Холодок»

Вкус напитка приятный, кисло-сладкий, освежающий, оставляет мятное послевкусие. Аромат легкий, свежий. Напиток бесцветный, прозрачный, с блеском.

\section{Выводы}

1. В качестве целевых компонентов подобраны минеральные вещества в виде соединений неорганических солей $\mathrm{CaCl}_{2}, \mathrm{MgCl}_{2}$, $\mathrm{Zn}\left(\mathrm{CH}_{3} \mathrm{OO}\right)_{2}$. Дозировки солей подобраны исходя из вкусовых качеств полученных растворов.

2. Осуществлен подбор витаминного комплекса, состоящий из витаминов $\mathrm{C}, \mathrm{B}_{1}, \mathrm{~B}_{6}, \mathrm{~B}_{12}$.

3. На основе подобранного витаминноминерального комплекса с использованием энергетических составляющих, таких как экстракт гуараны, эхинацеи, L-карнитина, и вкусовых компонентов сахара и лимонной кислоты разработана рецептура напитка «Холодок» и определены его физико-химические и органолептические показатели.

\section{Литература}

1. Пермякова Л.В., Сергеева И.Ю., Елонова Н.Н. Общие методы анализа сырья, полуфабрикатов и готовой продукции бродильных производств: лаборатор. практикум / Кемеровский технологический институт пищевой промышленности. - Кемерово, 2009. - 160 с.

2. Основы клинического питания: пер. с англ. - Петрозаводск: ИнтелТек, 2003. - 412 с.

3. Пищевые продукты и питание: 9-й доклад Объединенного комитета ФАО/ВОЗ по питанию (Серия технических докладов ВОЗ № 584). - M., 2000. - С. 39.
4. Смолянский Б. Лифряндский В.Г. Диетология: новейш. справ. для врачей. - СПб.: Сова; М.: Эксмо, 2003. - 816 с.

5. Тутельян В.А., Суханов Б.П., Булаев В.М. К вопросу о безопасности биологически активных добавок к пище растительного происхождения // Актуальные проблемы создания новых лекарственных препаратов природного происхождения: мат-лы VII междунар. съезда (3-5 июля 2003 г., СанктПетербург). - Пушкин, 2003. - С. 469-471.

6. Тутельян В.А Спиричев В.Б Суханов Б.П. [и др.]. Микронутриенты в питании здорового и больного человека: справ. руководство по витаминам и минеральным веществам. - М.: Колос, 2002. - 29 с.

7. Шабров А.В., Дадали В.A Макаров В.А. Биохимические основы действия микронутриентов пищи. - М., 2003.

8. Диетология: руководство / под ред. А.Ю. Барановского. - М.: Спутник врача, 2006. - $1188 \mathrm{c}$.

9. Evans, M., Guthrie, N., Pezzullo, J., (...), Fielding, R.A., Bellamine, A. Efficacy of a novel formulation of L-Carnitine, creatine, and leucine on lean body mass and functional muscle strength in healthy older adults: A randomized, double-blind placebo-controlled study,2017Nutrition and Metabolism14(1),7.

10. Daneshi-Maskooni, M., Keshavarz, S.A., Qorbani, M., (...), Jazayeri-Tehrani, S.A., Sotoudeh, G. 11Green cardamom increases Sirtuin-1 and reduces inflammation in overweight or obese patients with non-alcoholic fatty liver disease: A double-blind randomized placebo-controlled clinical trial 2018.

11. Miyazawa, T., Nakagawa, K., Kim, S.H., (...), Azzi, A., Meydani, M. Curcumin and piperine supplementation of obese mice under caloric 
restriction modulates body fat and interleukin1及,2018Nutrition and Metabolism 15(1),12.

12. Fuchs, D., Nyakayiru, J., Draijer, R., (...), Eijsvogels, T.M.H., Thijssen, D.H. Impact of flavonoid-rich black tea and beetroot juice on postprandial peripheral vascular resistance and glucose homeostasis in obese, insulinresistant men: A randomized controlled trial2016Nutrition and Metabolism.

13. Kennedy, D.O., Stevenson, E.J., Jackson, P.A., (...), Forster, J., Haskell-Ramsay, C.F. Multivitamins and minerals modulate whole-body energy metabolism and cerebral blood-flow during cognitive task performance: A double-blind, randomised, placebocontrolled triaNutrition and Metabolism201613(1),11.

14. Ranasinghe, P., Wathurapatha, W.S., Ishara, M.H., (...), Katulanda, P., Constantine, G.R. Effects of Zinc supplementation on serum lipids: A systematic review and metaanalysisNutrition and Metabolism 12(1),262015.

15. Luna, R.C.P., Dos Santos Nunes, M.K., Monteiro, M.G.C.A., (...), Rodrigues Gonçalves, M.D.C., De Carvalho Costa, M.J. a-Tocopherol influences glycaemic control and miR-9-3 DNA2018Nutrition and Metabolism 15(1),49.

16. Park, C.Y., Chung, J., Koo, K.-O., Kim, M.S., Han, S.N. Hepatic iron storage is related to body adiposity and hepatic inflammation2017Nutrition and Metabolism14(1),14.

\section{Literatura}

1. Permyakova L.V., Sergeeva I.Yu., Elonova N.N. Obshchie metody analiza syr'ya, polufabrikatov i gotovoj produkcii brodil'nyh proizvodstv: laborator. praktikum / Kemerovskij tekhnologicheskij institut pishchevoj promyshlennosti. Kemerovo, 2009. - $160 \mathrm{~s}$.

2. Osnovy klinicheskogo pitaniya: per. s angl. Petrozavodsk: IntelTek, 2003. - $412 \mathrm{~s}$.

3. Pishchevye produkty i pitanie: 9-j doklad Ob"edinennogo komiteta FAO/VOZ po pitaniyu (Seriya tekhnicheskih dokladov VOZ № 584). - M., 2000. - S. 39.
4. Smolyanskij B. Liflyandskij V.G. Dietologiya: novejsh. sprav. dlya vrachej. - SPb.: Sova; M.: Eksmo, 2003. - $816 \mathrm{~s}$.

5. Tutel'yan V.A., Suhanov B.P., Bulaev V.M. $\mathrm{K}$ voprosu 0 bezopasnosti biologicheski aktivnyh dobavok $k$ pishche rastitel'nogo proiskhozhdeniya // Aktual'nye problemy sozdaniya novyh lekarstvennyh preparatov prirodnogo proiskhozhdeniya: mat-ly VII mezhdunar. s"ezda (3-5 iyulya 2003 g., Sankt-Peterburg). - Pushkin, 2003. - S. 469471.

6. Tutel'yan V.A Spirichev V.B Suhanov B.P. [idr.]. Mikronutrienty $\mathrm{v}$ pitanii zdorovogo $\mathrm{i}$ bol'nogo cheloveka: sprav. rukovodstvo po vitaminam i mineral'nym veshchestvam. - M.: Kolos, 2002. $-29 \mathrm{~s}$.

7. Shabrov A.V., Dadali V.A Makarov V.A. Biohimicheskie osnovy dejstviya mikronutrientov pishchi. - M., 2003.

8. Dietologiya: rukovodstvo / pod red. A.Yu. Baranovskogo. - M.: Sputnik vracha, 2006. $1188 \mathrm{~s}$

9. Evans, M., Guthrie, N., Pezzullo, J., (...), Fielding, R.A., Bellamine, A. Efficacy of a novel formulation of L-Carnitine, creatine, and leucine on lean body mass and functional muscle strength in healthy older adults: A randomized, double-blind placebo-controlled study,2017Nutrition and Metabolism14(1),7.

10. Daneshi-Maskooni, M., Keshavarz, S.A., Qorbani, M., (...), Jazayeri-Tehrani, S.A., Sotoudeh, G. 11Green cardamom increases Sirtuin-1 and reduces inflammation in overweight or obese patients with non-alcoholic fatty liver disease: A double-blind randomized placebo-controlled clinical trial 2018.

11. Miyazawa, T., Nakagawa, K., Kim, S.H., (...), Azzi, A., Meydani, M. Curcumin and piperine supplementation of obese mice under caloric restriction modulates body fat and interleukin13,2018Nutrition and Metabolism 15(1),12.

12. Fuchs, D., Nyakayiru, J., Draijer, R., (...), Eijsvogels, T.M.H., Thijssen, D.H. Impact of flavonoid-rich black tea and beetroot juice on postprandial peripheral vascular resistance and glucose homeostasis in obese, insulinresistant men: A randomized controlled trial2016Nutrition and Metabolism. 
13. Kennedy, D.O., Stevenson, E.J., Jackson, P.A., (...), Forster, J., Haskell-Ramsay, C.F. Multivitamins and minerals modulate wholebody energy metabolism and cerebral bloodflow during cognitive task performance: A double-blind, randomised, placebo-controlled triaNutrition and Metabolism201613(1),11.

14. Ranasinghe, P., Wathurapatha, W.S., Ishara, M.H., (...), Katulanda, P., Constantine, G.R. Effects of Zinc supplementation on serum lipids: A systematic review and meta-
analysisNutrition

and

Metabolism 12(1),262015.

15. Luna, R.C.P., Dos Santos Nunes, M.K., Monteiro, M.G.C.A., (...), Rodrigues Gonçalves, M.D.C., De Carvalho Costa, M.J. a-Tocopherol influences glycaemic control and miR-9-3 DNA2018Nutrition and Metabolism 15(1),49.

16. Park, C.Y., Chung, J., Koo, K.-O., Kim, M.S., Han, S.N. Hepatic iron storage is related to body adiposity and hepatic inflammation2017Nutrition and Metabolism14(1),14. 